\title{
El papel de las imágenes en una investigación con jóvenes desde un enfoque cercano a la investigación basada en las artes
}

O papel das imagens numa investigação com jovens a partir de um enfoque próximo da investigação baseada nas artes

The role of images in research with young people from a perspective close to the arts-based research

\begin{abstract}
Alfred Porres Pla
alfredporres@telefonica.net

Profesor de educación secundaria y miembro del grupo de investigación consolidado "Esbrina. Subjectivitats i entorns educatius contemporanis" (2009SGR 0503) de la Universidad de Barcelona
\end{abstract}

\section{RESUMEN}

En el presente artículo reflexiono sobre el papel de las imágenes en una investigación educativa con jóvenes desde un enfoque cercano a la investigación basada en las artes. A diferencia de otras formas de indagación que recurren a ella como fuente de evidencias, instrumento de documentación o como una mera ilustración, la imagen es aquí considerada como una encrucijada para el encuentro, un centro de vibraciones - donde todo resuena en vez de sucederse o corresponderse- que nos permite vislumbrar aquello que de otro modo permanecería inexplorado.

Palabras-clave: Investigación con jóvenes, investigación basada en imágenes, investigación basada en las artes.

\section{RESUMO}

No presente artigo reflito sobre o papel das imagens numa investigação educativa com jovens a partir de um enfoque próximo da perspetiva da investigação baseada nas artes. Em contraste com outras formas de indagação que recorrem a ela como fonte de evidências, instrumento de documentação ou como uma mera ilustração, a imagem é aqui considerada como uma encruzilhada para o encontro, um centro de vibrações - no qual tudo ressoa em vez de suceder-se ou corresponder-se - que nos permite vislumbrar aquilo que de outro modo permaneceria inexplorado.

Palavras-chave: Investigação com jovens; investigação baseada em imagens; investigação baseada nas artes. 


\section{ABSTRACT}

The current article reflects on the role of images in an educative investigation with young people from a nearly arts-based research approach. Unlike other investigation forms which resort to the image as a source of evidence, means of documentation or as a mere picture, it is here considered as a crossroads to meet, a vibrations center -where everything echoes instead of following or fitting- which allows us to glimpse what in other contexts would remain unexplored.

Keywords: Research with Young People, Image-based Research, Arts-based Research. 


\section{INTRODUCCIÓN}

Mi primer contacto con la investigación basada en las artes se produjo durante el curso 2007-2008, en un seminario del programa de doctorado Artes visuales y educación: un enfoque construccionista de la Facultad de Bellas Artes de la Universidad de Barcelona. A lo largo del seminario tuvimos la oportunidad de estudiar algunas propuestas que se presentaban como ejemplos de investigación basada en las artes. Ensayos visuales en los que las imágenes contaban por sí mismas un relato, o dialogaban (no ilustraban) desde otro plano con lo que se exponía en el texto. Ensayos que, mediante el uso de formas literarias, permitían al lector entrar en el relato y conectarlo con su propia experiencia.

Investigaciones que daban cuenta del proceso seguido y de sus hallazgos a través de formas no convencionales de representación en un informe de investigación, por ejemplo mediante representaciones visuales o performativas. El modo de aproximarnos a los distintos enfoques metodológicos que estudiamos en el seminario respondía a un posicionamiento que Joe L. Kincheloe (2004: 4) resumió con una pregunta provocadora: “¿Quién dijo que la investigación se debe hacer de este modo?". Para ello, abordamos cada propuesta metodológica con el ánimo de explorarla como autores, para comprender sus posibilidades y sus límites, aquello que nos ofrecía y nos negaba. En mi caso, este proceso formativo corrió paralelo al desarrollo de mi propia investigación de tesis doctoral. La experiencia que acompaña las reflexiones de este artículo forma parte del relato de dicha investigación.

El curso 2008-2009, el Departamento de Educación de la Generalitat de Catalunya me concedió una licencia retribuida que me eximía del ejercicio de la docencia durante un año para poder dedicarme a la investigación. Así que, cuando a finales del curso 2007-2008 me notificaron que mi proyecto de investigación para el curso siguiente había sido aprobado, solicité el consentimiento de mis estudiantes de ese curso para usar el material que habíamos producido juntos en nuestras clases de educación visual. La noticia de que el curso siguiente no sería profesor en el instituto les sorprendió. Todos ellos y ellas accedieron a que utilizara sus aportaciones de ese año y más de cincuenta se ofrecieron, además, a participar el curso siguiente en la investigación. El propósito de la investigación que llevamos a cabo juntos era comprender cómo los sujetos implicados en la relación pedagógica negociaban su identidad para poder habitar las subjetividades que les ofrecía la escuela. Para ello, propuse a mis estudiantes que ahondáramos en las múltiples experiencias de 'ser con otros' - con los amigos y las amigas, en el instituto, a través del MSN, etc. - en las que se implicaban cotidianamente y en la diversidad de estrategias de relación y formas de mostrarse que desplegaban en cada una de ellas. De conseguir trazar los nexos entre esas subjetividades y las prácticas de socialización que las invocaban, quizás pudiéramos obtener algún atisbo de comprensión sobre el modo en que ellos y ellas construían - colectiva y cotidianamente- su sentido de ser. Éste fue fundamentalmente el encargo al que se aplicaron los treinta y tres chicos y chicas que finalmente colaboraron en la investigación.

En el presente artículo explico el papel que jugaron las imágenes en nuestro proceso de indagación. A medida que fueron avanzando en su relato, las experiencias que mis estudiantes compartieron para la investigación quedaron cosificadas en una representación impersonal -cuya manifestación más visible era la narración en tercera persona. La incorporación de las imágenes pretendía restituir la dimensión subjetiva y corporal de lo vivido, así como acceder a un conocimiento situado, corporeizado, casi táctil, que nos alejara del territorio domesticado por el que habíamos transitado hasta entonces.

\section{LA IMAGEN COMO ENCRUCIJADA DE ENCUENTROS}

Los conceptos son centros de vibraciones, cada uno en sí mismo y los unos en relación con los otros. Por esta razón todo resuena, en vez de sucederse o corresponderse.

GILLES DELEUZE y FÉLIX GUATTARI (1993: 28)

Nuestra primera incursión en las experiencias cotidianas de mis estudiantes consistió en construir una nube de pa- 
labras que definiera lo que, para ellos y ellas, era valioso del tiempo que pasaban con otros. Unos condensaban su experiencia en tres palabras, otros usaban una docena. En total reunimos ciento cincuenta y dos palabras que, descontando las que se repitieron, nos remetían a ochenta y tres conceptos diferentes. La confianza — seguida de lejos por la libertad, la diversión y la desconexión de la rutina del día a día- fue el foco de significación más repetido. Sin embargo, lo verdaderamente valioso no fue tanto la constatación de esa reiteración como la riqueza y la diversidad de significados que aglutinaba.

GEMMA y ANDREA G: La confianza nos facilita hablar y actuar como naturalmente pensamos y somos.

EUGÈNIA: Si falla la confianza, falla todo. Confiar en una persona es creer en ella, respetarla y mostrar seguridad y protección hacia ella.

ELENA NZ y MARCELA: Saber que siempre que le necesite estará allí para ayudarme y que, diga lo que diga, siempre quedará entre nosotros.

ROSA: Poder contar con alguien, sentirme a gusto y saber que, si tengo algún problema, estará para levantarme de la caída.

MARCELA: Confiar en mí misma, que no me afecte lo que digan los demás y así poder llegar a algún lugar en la vida.

ANDREA B: Compañerismo, complicidad, estima, apoyo y confianza son sentimientos y emociones que me transmite la música hacia los otros. Cuando puedo compartir con alguien mi música experimento una sensación y unos vínculos muy fuertes.

ELENA NV, RICARD y ANDREU: La confianza en la noche tiene un aspecto muy diferente a la confianza 'habitual'. La confianza habitual es el cariño, el apoyo, el 'poder contar con', que cuesta mucho tiempo de adquirir en situaciones normales. De noche, en cambio, estas fronteras se esfuman, son más transparentes y traspasables. La confianza parece ser muy fácil, pero efímera.

ANNA: Todas las manos unidas. Significa que hay una gran amistad, confianza, como una estrella que brilla por sí sola.

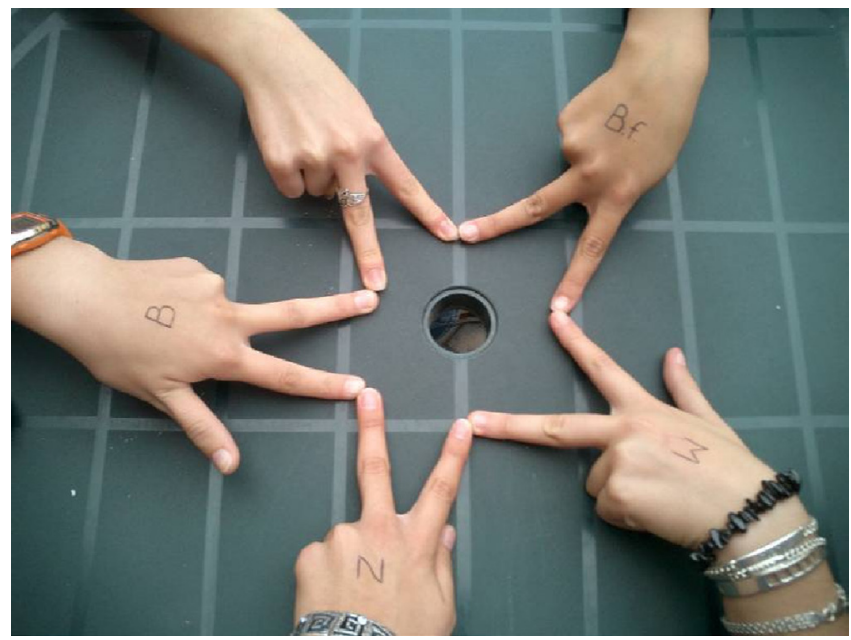

Confianza. Narrativa visual de Anna (curso 2008-2009)

Pero, en el decurso de nuestra investigación, los conceptos se fueron convirtiendo en una sarta de definiciones cada vez más alejadas de la experiencia vivida por mis estudiantes. Nuestras conversaciones se agotaban en un recorrido circular - un toma y daca de preguntas y respuestas manidas que nos devolvían irremisiblemente al lugar del que habíamos partido- y las resonancias posibles se apagaban antes de que pudiéramos ahondar en el significado que cada uno de ellos y ellas otorgaban a su experiencia. De ahí que empezáramos a experimentar con estrategias visuales de indagación desde una perspectiva próxima a la investigación basada en las artes.

Bajo el amplio paraguas de la investigación basada en las artes se reúnen una gran variedad de prácticas de investigación (Barone y Eisner, 2006; Irwin, 2004) que se sirven de procedimientos artísticos (literarios, visuales, performativos, etc.) para explorar aspectos de la experiencia que mediante otras formas de investigación suelen quedar inexplorados. Esto es debido a que, por ejemplo, mientras la ciencia tiende a reducir la experiencia a un conjunto de principios fundamentales, el arte la amplifica y la expande (McNiff, 2008: 34).

Lo poético como distinto de lo prosaico, lo artístico como distinto de lo científico, la expresión como distinta de la enunciación, hacen algo que no es conducir a una experiencia. Constituyen una experiencia. 
La investigación basada en las artes (Finley, 2008: 72) aprovecha la dimensión personal, corporal y afectiva de la experiencia, la imaginación y la emoción, así como el intelecto, como formas de conocer y responder al mundo. Asimismo, concede licencia interpretativa al investigador para crear significados a partir de la experiencia y reconoce el papel fundamental de la forma en la construcción del significado. Por todo ello, la investigación basada en las artes transita siempre entre fronteras borrosas, formas híbridas y continuas tensiones, de entre las que Elliot Eisner (2008: 19-24) destaca las siguientes:

-El deseo de trabajar imaginativamente frente a la necesidad de producir resultados comunicables.

-El ahínco en enfocar las condiciones particulares de una situación educativa para iluminar sus características distintivas y, al mismo tiempo, desarrollar observaciones e ideas que conciernan a una audiencia mucho más amplia.

-El tira y afloja entre lograr un producto con cualidades estéticas y, a la vez, lograr un trabajo con, al menos, algún grado de verosimilitud.

-La tendencia a formular preguntas — cada vez más refinadas, cada vez más informadas, pero siempre orientadas a llevar la investigación hacia un final abierto - frente al imperativo de producir respuestas definitivas.

-La diferencia entre la construcción metafórica del significado y la utilidad literal de la investigación.

A lo largo del tiempo que compartimos en nuestra investigación ensayamos múltiples formas de entrar en la conversación cultural que nos ocupaba. El debate en grupo, la conversación privada, la escritura - ya fuera introspectiva o dialógica $(M S N)$-, la entrevista grabada, etc. Nuestras narrativas visuales se inscribían en esta estrategia más amplia por diversificar las formas de encontrarnos y participar en la construcción del significado, a sabiendas de que las múltiples perspectivas estéticas que nos proporcionan las metodologías de investigación basada en las artes promueven "espacios para el empoderamiento, la construcción del conocimiento y la inclusión" (de Mello, 2007: 219). De todos modos, la nuestra nunca fue una investigación basada en las artes. No era éste nuestro propósito fundacional y, aunque las metodologías se hacen más que se definen, tampoco llegamos a adentrarnos lo suficiente en ese territorio como para poder reconocer que nos lo apropiáramos. Aun así, el papel que reservamos a la imagen (fotográfica) en nuestra investigación era más próximo a las metodologías de investigación basada en las artes que a otras formas de investigación que recurren a ella como fuente de evidencias, instrumento de documentación o como una mera ilustración. Desde una perspectiva próxima a la investigación basada en las artes, el valor de las imágenes visuales en una investigación se fundamenta, al menos, en los argumentos siguientes (Weber, 2008: 44-47):

-Las imágenes pueden ser usadas para capturar lo inefable, aquello difícil-de-explicar-en-palabras.

-Las imágenes pueden hacernos prestar atención a las cosas de una forma nueva y diferente.

-Las imágenes suelen ser memorables.

-Las imágenes se pueden usar para comunicar más holísticamente, incorporando múltiples capas y evocando historias y preguntas.

-Las imágenes pueden mejorar la comprensión empática y la generabilidad.

-A través de la metáfora y el símbolo, las imágenes artísticas pueden comunicar conceptos teóricos de forma elegante y elocuente.

-Las imágenes fomentan el conocimiento corporeizado.

-Las imágenes pueden ser más accesibles que muchas formas de discurso académico.

-Las imágenes pueden facilitar la reflexividad en el diseño de la investigación.

-Las imágenes provocan acción para la justicia social. 


\section{LAS NARRATIVAS VISUALES}

La ciencia afirma significados;

el arte los expresa.

JOHN DEWEY (1949: 76)

Nuestras narrativas visuales estaban formadas por un conjunto de imágenes, habitualmente fotográficas, que cada chico y cada chica había reunido para relatar su experiencia cotidiana de 'ser en relación'. La procedencia de las imágenes era de lo más variopinta - desde instantáneas rescatadas de sus álbumes personales hasta collages elaborados meticulosamente para la ocasión- y su realización abarcaba un amplio abanico de formas y estrategias fotográficas de representación - desde las más literales y figurativas a otras pretendidamente metafóricas. La estructura narrativa del conjunto de imágenes que constituían cada narrativa visual también se articulaba de múltiples formas. Algunas se ordenaban siguiendo una secuencia lineal, mientras que otras se repartían en torno a focos de significación -ya fuera acumulando muchas imágenes en cada tema o, por el contrario, elaborando concienzudamente una imagen que lo sintetizara.

Inicialmente, no teníamos una denominación específica para referirnos a esa dimensión visual de nuestra investigación. 'Narrativa visual', 'diaporama', incluso 'nube de imágenes', eran algunas maneras de nombrar el conjunto de imágenes que mis estudiantes reunieron para documentar la experiencia de 'ser en relación' que decidieron compartir en la investigación. El término 'narrativa visual' se extendió poco a poco, como una mancha de aceite, hasta imponerse. Pero las significaciones que cada uno de ellos y ellas le otorgaba solamente se pueden rastrear a través de las imágenes que compartimos y de las transcripciones de nuestras conversaciones en torno a ellas.

Una de las estrategias de exploración inicial más extendidas fue rebuscar entre sus álbumes personales.

EUGÈNIA: Ahora, siempre que vas a algún sitio con los amigos, está de moda hacer fotos. Casi siempre estamos haciendo fotos, así que he elegido algunas.

(Entrevista con Eugènia, 8 de mayo de 2009)

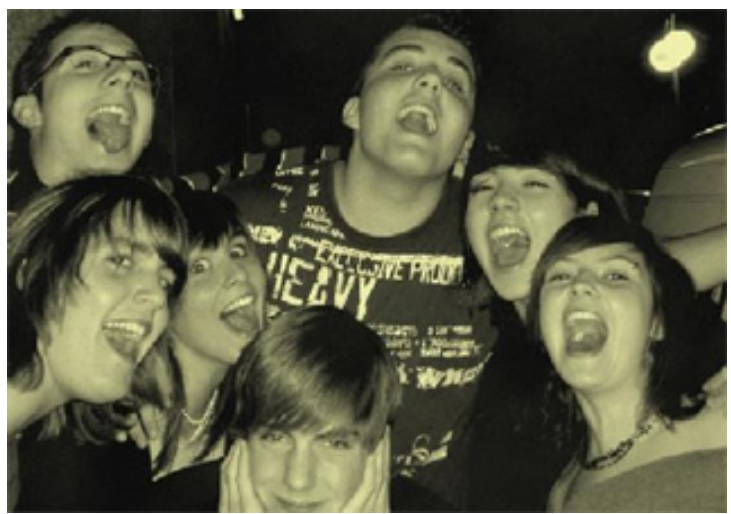

Confianza, seguridad, comodidad. Narrativa visual de Eugènia (curso 2008-2009)

Sin embargo, la profusión de imágenes que producían y guardaban en sus dispositivos electrónicos - teléfono móvil, cámara digital, ordenador - amenazaba con colapsar la posibilidad de trenzar una narrativa visual apropiada.

BERTA F: Lo más difícil era decidirse porque, al abrir cada carpeta, todas las imágenes que encontraba me servían. Son 'mis instantáneas', así es como yo las llamo, y me ha costado hacer una selección.

(Entrevista con Berta F y Mireia, 25 de mayo de 2009)

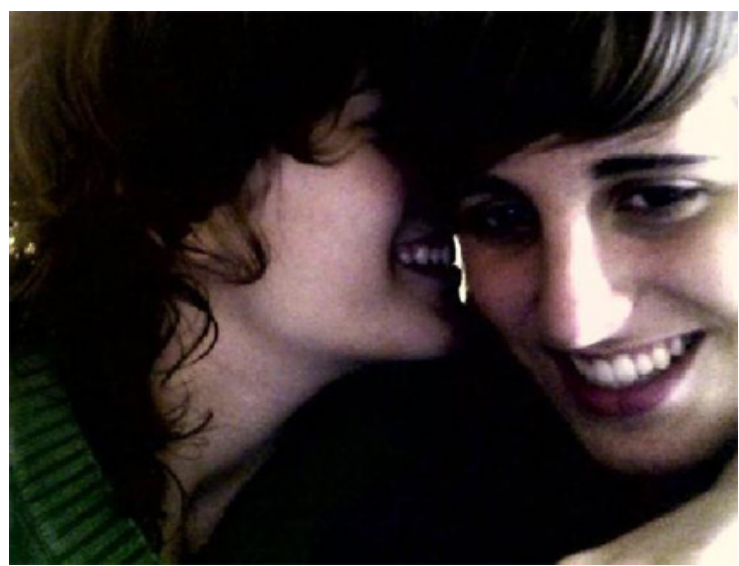

Momentos de chicas. Narrativa visual de Berta F (curso 2008-2009).

Otra vía que abordaron consistía en producir unas imágenes específicas para construir su narrativa visual. "Clasifiqué las palabras en tres grupos y pensé en situaciones que las representaran. A continuación, intenté encontrar la relación entre mis palabras y la imagen que construía" (Conrado). 
Algunos intentos fueron infructuosos. "Comenzamos realizando algunas fotografías, pero no nos parecían significativas, es decir, no reflejaban lo que buscábamos de nuestra amistad” (Andrea G y Gemma); “Me colapsé con la idea literal de cada palabra y no sabía como salirme" (Maria); "Me costaba encontrar imágenes que no fueran literales pero que expresaran lo que quería" (Eduard).

La metáfora visual se erigió en una forma de esquivar las interpretaciones más literales, para acceder a la expresión de lo inefable de la experiencia. "Las imágenes nos aportaron momentos y situaciones que sería difícil explicar con palabras" (Conrado); "A diferencia de las palabras, que siempre son 'o blanco o negro', las imágenes se pueden comprender de una u otra manera, según la imaginación o la manera de ser de cada uno" (Ricard, Elena Nv, Andreu); "Las imágenes han influido mucho en nuestra comprensión, nos han aportado sentimientos que las palabras no pueden describir" (Rosa, Roger).

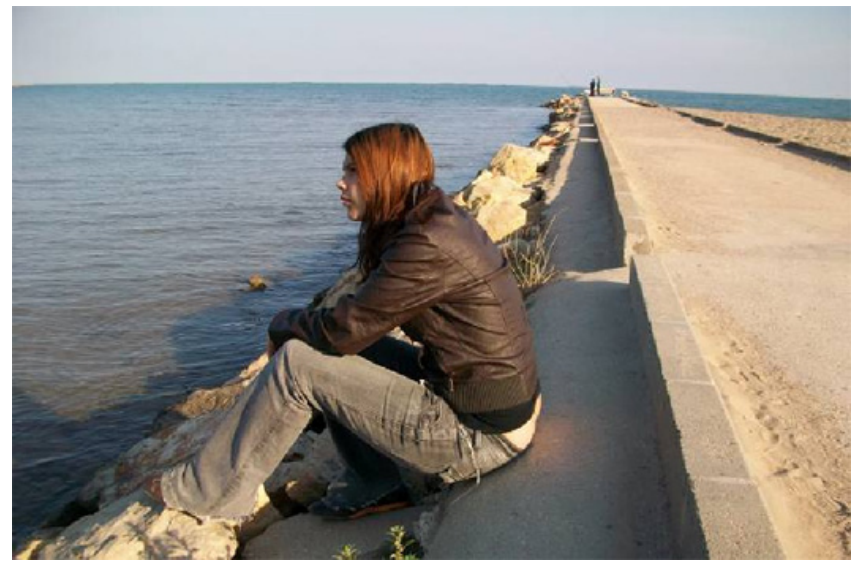

Desconexión. Narrativa visual de Rosa (curso 2008-2009)

La arena de nuestro debate era el significado -cómo se construía, para quién- y el papel de las imágenes en este proceso.

La clave fue pensar en nuestra nube de palabras a partir de nuestras propias experiencias, ir más allá del significado literal de cada palabra e intentar que la imagen que construíamos no sustituyera la palabra, sino que la complementara.

(Ricard, Elena Nv, Andreu)
El esfuerzo por capturar el sentido de lo vivido propiciaba la emergencia de estrategias que perseguían revivir la experiencia, performarla.

ANDREA B: Pensé en las sensaciones que tenía, por ejemplo, en los conciertos, o cuando escuchaba música con los amigos. También, por ejemplo, escuchaba una canción y escribía sobre las sensaciones que me producía.

(Entrevista con Andrea B, 18 de mayo de 2009)

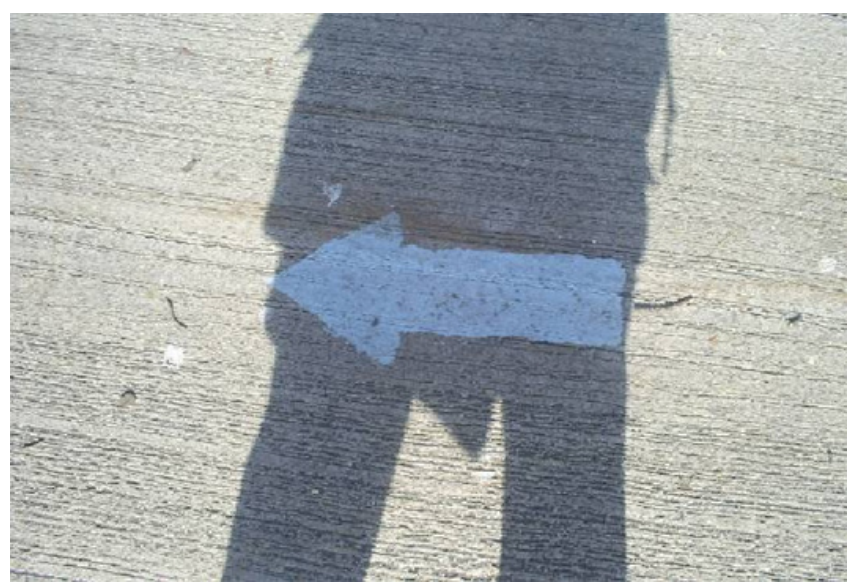

Ideología. Narrativa visual de Andrea B (curso 2008-2009)

A través de performar el momento, las imágenes restituían la corporeidad de la vivencia.

GEMMA: Un día nos encontramos y ipam! nos abrazamos. El sentimiento que expresa es lo que intentábamos plasmar al hacer la foto.

(Entrevista con Gemma y Andrea G, 12 de mayo de 2009)

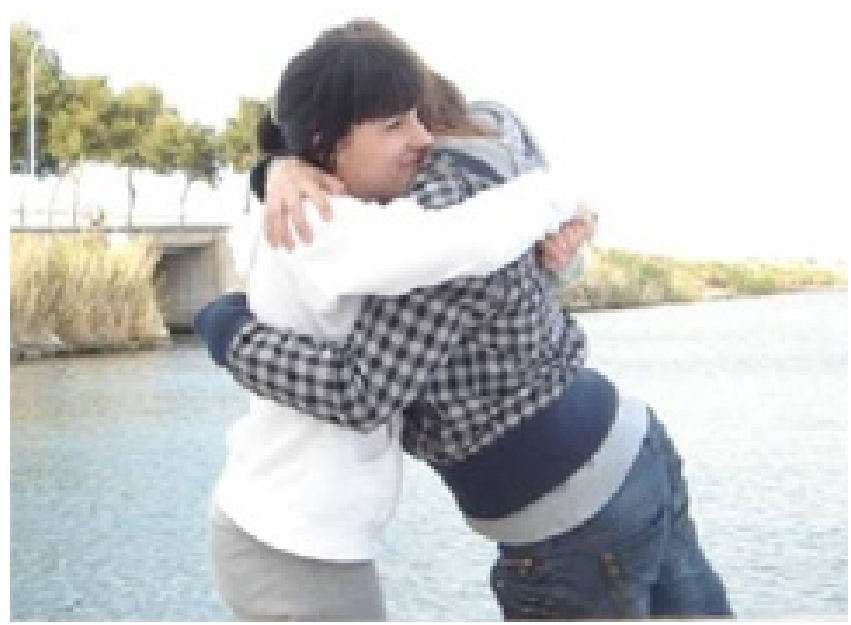

Consuelo. Narrativa visual de Andrea G y Gemma (curso 2008-2009) 
En definitiva, como explica Ian Kaplan (2008: 185-186):

El medio de la fotografía permite representaciones tanto literales y más figurativas como metafóricas (y por supuesto ambas posibilidades se pueden dar simultáneamente en la misma imagen). La fotografía participativa no necesita ser una actividad pautada rígidamente en el sentido de que los participantes deben decidir primero lo que van a fotografiar, hacer sus fotografías y sólo entonces analizar las imágenes resultantes. Además, el proceso de captura de imagen no necesita ser concebido como un medio de representar la realidad objetiva (un concepto que, en cualquier caso, es problemático). La espontaneidad puede ser una parte importante del proceso, y algunas de las fotografías más interesantes para los propósitos de un proyecto pueden ser accidentales o incluso construidas para ser deliberadamente simbólicas.

(KAPLAN, 2008: 185-186)

Para Hedy Bach (2001) la investigación a partir de narrativas visuales se basa en el uso de la fotografía para evocar la memoria de nuestras vidas, una memoria en torno a la que construimos y reconstruimos nuestras historias de vida. Pero, a diferencia de la memoria, las fotografías en sí mismas no preservan significado alguno. Nos ofrecen apariencias - con toda la credibilidad y la gravedad que normalmente prestamos a dichas apariencias-, un signo despojado de su significado. Por esta razón, continúa Hedy Bach, el significado siempre tiene lugar en el tiempo y a través de la narración. Las fotografías en sí mismas no narran, solamente capturan las apariencias instantáneas que empleamos en nuestro relato. La fotografía ralentiza el tiempo, lo segmenta en momentos que pueden ser estudiados. Pero el significado siempre emerge de la tarea de volver una y otra vez sobre ello.

Los eventos encuentran su significado en el encuentro estético, donde el conocimiento es construido y reconstruido en cada situación singular. En este sentido, una obra de arte re- almente existe sólo en el encuentro dialógico. Encerrada en una bóveda oscura, una pintura es simplemente un agregado de materiales. La estética, como la educación, es el proceso de llegar a ser y recrearse en cada nuevo contexto.

(SLATTERY, KRASNY Y O’MALLEY, 2006: 550)

Por eso, siempre concebí las narrativas visuales como una encrucijada para el encuentro, un enclave donde reanudar nuestra conversación cultural sobre el significado que cada uno y cada una de mis estudiantes otorgaban a sus experiencias cotidianas de 'ser en relación', retomar los conceptos que inicialmente asociaban a dichas experiencias e intentar que resonaran, en vez de permitir que simplemente se sucedieran o correspondieran. Para empezar, como hicieron Andrea G y Gemma, las imágenes nos permitían rescatar dichos conceptos desde la proximidad corporeizada de la experiencia vivida que capturaban en sus instantáneas.

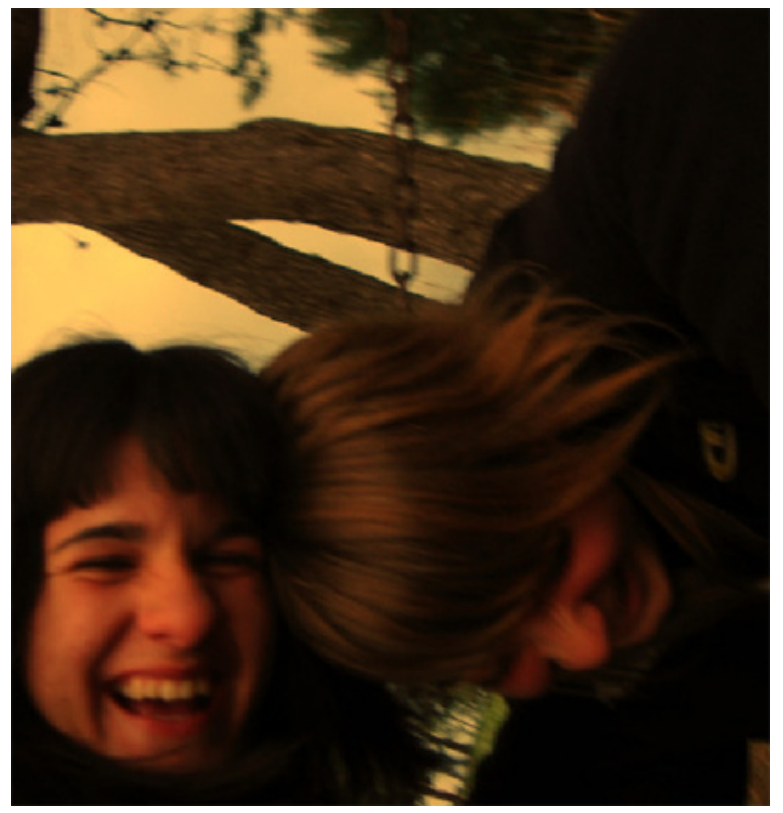

Felicidad. Narrativa visual de Andrea G y Gemma (curso 2008-2009)

Un día salimos de excursión las dos solas en bicicleta. Cuando paramos a descansar, nos entró la risa y nos hicimos esta fotografía. Para nosotras refleja un momento de alegría que nos proporciona nuestra amistad.

(ANDREA G Y GEMMA) 


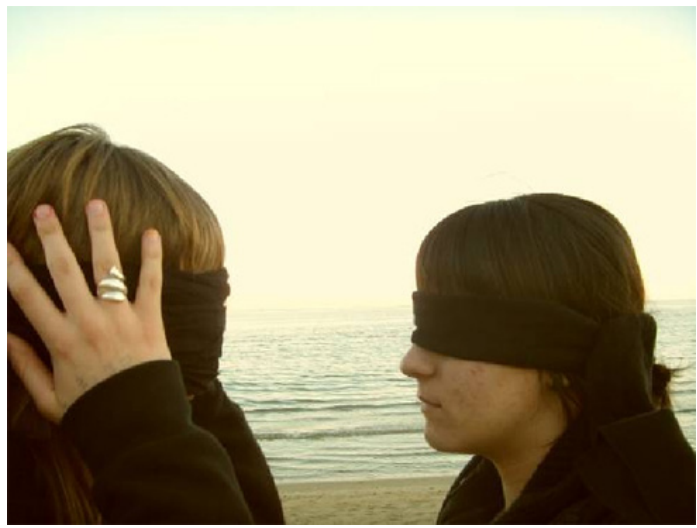

Comprensión. Narrativa visual de Andrea G y Gemma (curso 2008-2009)

La amistad no es sólo lo que ves, sino lo que sentimos la una por la otra. No necesitamos ver el exterior, lo que importa es nuestro interior. No necesitamos vernos para comprendernos, para saber si la otra es o no feliz. Solamente con escuchar su voz, yo ya lo sé.

(ANDREA G Y GEMMA)

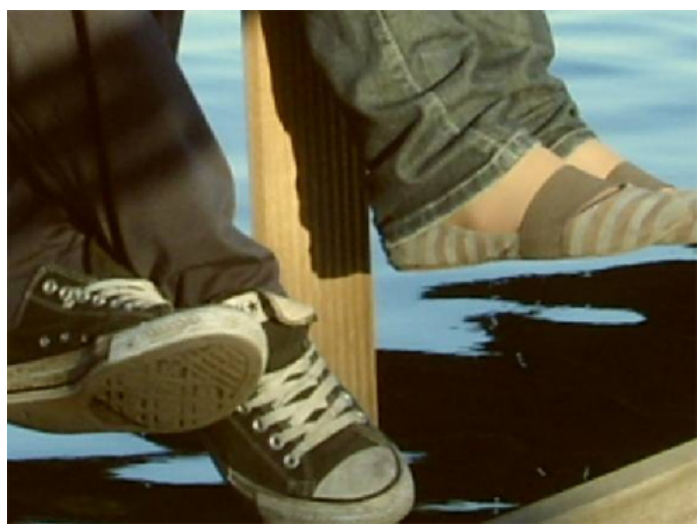

Cariño. Narrativa visual de Andrea G y Gemma (curso 2008-2009)

Esta fotografía refleja un momento de tranquilidad, un momento de conversación en que estamos solas, un momento de confesión, nuestro momento, un momento en el que solamente existimos nosotras.

(ANDREA G Y GEMMA)

Como sugiere Hedy Bach (2001), las fotografías tienden a objetivizar pero, a través del relato que las teje en una narrativa visual, se pueden convertir en 'objetos transicionales' hacia otra realidad. Para ello, el relato no puede limitarse a explicar la imagen, sino que debe perseverar en el empeño de expandirla. Detrás de cada historia siempre hay otra historia (Bach, 2001) y nuestras conversaciones perseguían explorarlas. Intentar, como en el caso de Eugènia, dialogar con la imagen y dialogar con las historias de dolor, nostalgia y pérdida que afloraban para atisbar, aunque fuera apenas por un momento, la subjetividad que se constituía en esa experiencia. Pero un encuentro conversacional no es simplemente un dispositivo de rastreo, una forma de escarbar en el recuerdo para desvelar unos significados que siempre estuvieron ahí. Más bien al contrario, un encuentro conversacional es un momento singular que provoca y "evoca un sonido diferente" del que emergen nuevas relaciones y significados. Para mí ese encuentro también constituía una oportunidad única para ahondar en el sentido de nuestra relación pedagógica y de las subjetividades que habitábamos al participar y vivir la experiencia de investigación que compartíamos. De ahí que, siguiendo a Elliot Eisner (1998: 50), nunca me acerqué a sus relatos con el propósito de examinar conductas, sino más bien para entablar una conversación cultural con ellos y ellas que nos permitiera percibir relaciones e interpretar significados. Usarlos -más que comprenderlos - para repensar y transformar la vivencia de nuestra relación escolar.

ALFRED: ¿Tú vinculas esta imagen a tus pensamientos sobre lo que dejas atrás cada vez que vas o vuelves de Moldavia?

EUGÈNIA: Sí, porque, cuando me fui de aquí, lloré. Yo me fui por dos meses y tenía miedo de irme porque ya hacía dos o tres años que no iba a Moldavia y no sabía qué me iba a encontrar. Al llegar allí me reencontré con mis amigos y mis abuelos y lloré al volver a verlos. Y, cuando tuve que emprender el camino de vuelta, lloré porque no sabía cuando regresaría, ni si volvería a verlos con vida, porque mis abuelos son ya muy viejos. Cuando llegué aquí también lloré, pero ya lloré de alegría. Porque, en los dos meses que pasé allí, lo encontré todo diferente, cambiado. De verdad, ya no me sentía... suya. Allí todo ha cambiado bastante y no lo aceptaba como mío. 
ALFRED: Y tú también habrás cambiado, seguramente.

EUGÈNIA: Sí, han cambiado mis amigos y ha cambiado la relación. De verdad, me da pena. Pero he de entender que nada puede ser igual que antes. Así es la vida, siempre cambia y cambia.

(Entrevista con Eugènia, 8 de mayo de 2009)

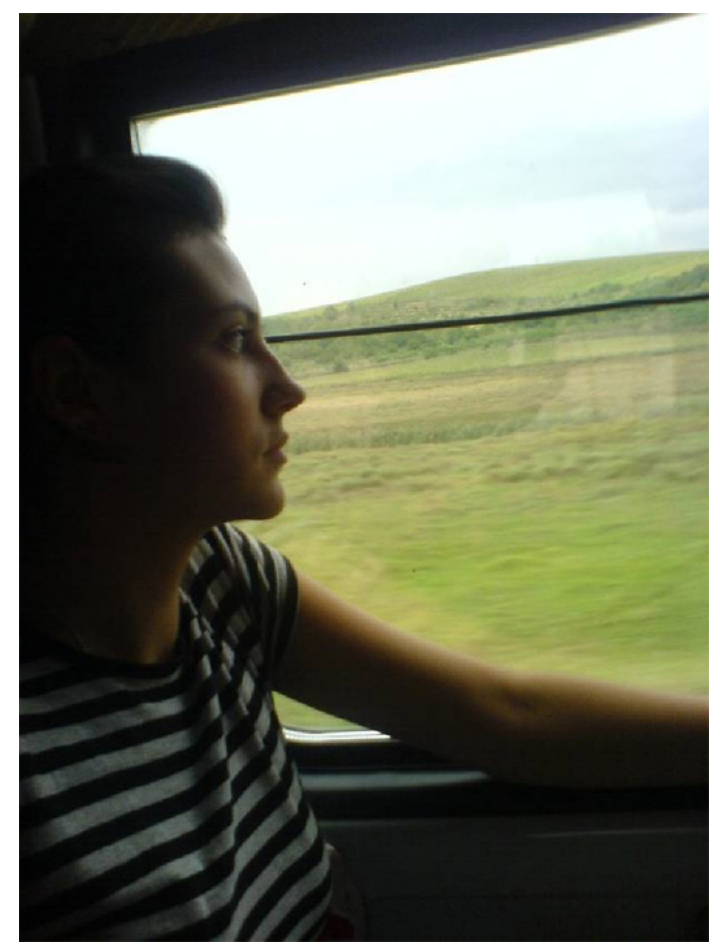

Tristeza. Narrativa visual de Eugènia (curso 2008-2009).

Yo pienso que, si existe la felicidad también debe existir la tristeza. Este sentimiento me produce vacío, dolor y pensamientos. En esta fotografía estoy en el tren de vuelta de Moldavia. El retorno me produce tristeza porque no sé si volveré a ver a mi familia. En la distancia, las cosas y las relaciones cambian. Cambio yo y cambian las personas. Nunca se sabe qué pasará en el futuro, como seguirán, como cambiarán nuestras relaciones. Pero también me produce esperanza, la esperanza de que todo saldrá bien.

(EUGÈNIA)
Empecé a tirar del hilo de esa madeja de significaciones en torno a lo que ellos y ellas consideraban valioso de sus experiencias cotidianas de 'ser en relación' para conectarlo con nuestra experiencia escolar. Era consciente de que ese hilo era demasiado delgado, demasiado fino para contener todas las interpretaciones posibles. En la tarea de desenredarlo siempre subyacía una pérdida, la renuncia a trazar otros recorridos. Aun así, con ese hilo tejí algunos de mis aprendizajes primordiales de nuestros encuentros.

\section{CONCLUSIONES}

Las metodologías no son compartimentos estancos - aunque lo puedan parecer sus definiciones-, ni son lugares en los que uno pueda ubicarse con comodidad, aunque con frecuencia también usemos esta metáfora para definirlas. Las metodologías se asemejan más a flujos y relaciones, lugares en estado gaseoso que se desvanecen con facilidad si dejamos de habitarlos. Por eso, más que un método o una técnica, la investigación basada en las artes es, desde mi punto de vista, un posicionamiento epistemológico. Lo que caracteriza la investigación basada en las artes no es tanto el uso de determinadas metodologías artísticas como el modo en que éstas se inscriben en la investigación, dónde se sitúan y, sobre todo, dónde nos sitúan. Con ello quiero decir que, más que la inclusión de imágenes o textos literarios, el resorte que activa una investigación basada en las artes es esencialmente epistemológico, un tipo de mirada que reconocemos en lo artístico y que nos permite vislumbrar aquello que mediante otras metodologías permanecería irremisiblemente inexplorado. Como epistemología vinculada al construccionismo (al menos éste es el enfoque desde el que la he abordado), no persigue conseguir "una explicación del mundo sino una explicación de nuestra relación con el mundo" (Kincheloe y Berry, 2004: 2). Como metodología, se halla en la intersección de otras tantas formas de abordar la realidad social que (Kincheloe y Berry, 2004: 2-3):

-rehúyen las miradas deterministas, -confían en la agencia del ser humano y -rechazan las formas estandarizadas de producción del conocimiento. 
Pero, bien sea camuflada como un ensayo visual o mimetizada en una investigación narrativa, la investigación basada en las artes se delata por su empeño en producir conceptos sobre el mundo social que no existían previamente. Más que encontrados, los significados son producidos en el contexto de la investigación, a través de lo que Joe L. Kincheloe (2004: 20) denominó 'rigor en la ausencia' y que consiste en:

-comprender que hay en el mundo mucho más de lo que podemos ver,

-imaginar lo que podría ser,

-desarrollar alternativas a las condiciones de opresión existentes,

-discernir lo que falta y promover la acción.

Abordar una investigación educativa con jóvenes desde un enfoque cercano a la investigación basada en las artes responde también a un posicionamiento estratégico y político que conviene reseñar. Nuestros estudiantes no siempre comparten nuestras formas de relación con los saberes, ni disponen de nuestras mismas herramientas intelectuales para interrogarlos. De ahí que debamos explorar formas de indagación que nos permitan reconocer y aproximarnos a sus propias formas de producción cultural. Por eso, el relato que construimos en torno a las fotografías que mis estudiantes decidieron compartir en nuestra investigación fue una invitación, no sólo a repensar el lugar que -ellos, ellas y yo mismo- ocupábamos en esa relación de investigación que cultivábamos, sino también a reconsiderar las formas tradicionales de circulación del saber. Hacer fotografías y compartirlas - a través de sus teléfonos móviles o mediante su publicación en fotologs - era una práctica habitual entre ellos y ellas. Lo que mi propuesta les sugería era que de ello también podíamos aprender.

\section{REFERENCIAS BIBLIOGRÁFICAS}

BACH, Hedy (2001): "The Place of the Photograph in Visual Narrative Research. (Project Statement)". Afterimage. <http://www.thefreelibrary.com/ The+Place+ of+the+Photograph+in+Visual+Narrative+Research.+(Project... -a080757500> [con acceso el 19 de julio de 2011]

BARONE, Tom y EISNER, Elliot (2006): "Arts-Based Educational Research". En GREEN, J.; CAMILLE, G. y BELMORE, P. [eds.] (2006): Handbook of Com- plementary Methods in Educacional Research. (pp. 95-109). Mahwah, New Jersey, AERA.

DE MELLO, Dilma Maria (2007): "The Language of Arts in a Narrative Inquiry Landscape". En CLANDININ, J. [ed.] (2007): Handbook of Narrative Inquiry (pp. 203-223). Thousand Oaks, CA: Sage Publications.

DELEUZE, Gilles y GUATTARI, Félix (1993): ¿Qué es la filosofía? Barcelona, Anagrama. (1991).

DEWEY, John (1949): El arte como experiencia. México, Fondo de Cultura Económica. (1930).

EISNER, Elliot (1998): El ojo ilustrado. Indagación cualitativa y mejora de la práctica educativa. Barcelona, Paidós Educador. (1990).

EISNER, Elliot (2008): "Persistent tensions in art-based research". En CAHNMANN-TAYLOR, M. y SIEGESMUND, R. [eds.] (2008): Arts-Based Research in Education. Foundations for Practice (pp. 16-27). New York and London, Routledge.

FINLEY, Susan (2008): "Arts-Based Research". En KNOWLES, J. G. y COLE, A. L. [eds.] (2008): Handbook of the Arts in Qualitative Research (pp. 71-81). Thousand Oaks, CA: Sage Publications.

IRWIN, Rita L. (2004): “A/r/tography: A metonymic métissage". En IRWIN R. L. y de COSSON, A. [eds.] (2004): A/r/tography: Rendering self through arts based living inquiry (pp. 27-38). Vancouver, BC, Pacific Educational Press.

KAPLAN, Ian (2008): “Being 'seen' being 'heard': engaging with students on the margins of education through participatory photography". En THOMSON, P. [ed.] (2008): Doing Visual Research with Children and Young People. (pp. 175-191). London and New York, Routledge.

KINCHELOE, Joe L. y BERRY Kathleen S. (2004): Rigour and Complexity in Educational Research. Conceptualizing the bricolage. London, Open University Press.

MCNIFF, Shaun (2008): “Art-Based Research". En KNOWLES, J. G. y COLE, A. L. [eds.] (2008): Handbook of the Arts in Qualitative Research (pp. 29-40). Thousand Oaks, CA: Sage Publications.

SLATTERY, Patrick; KRASNY, Karen A. y O'MALLEY, Michael Patrick (2006): "Hermeneutics, aesthetics, and the quest for answerability: a dialogic possibility for reconceptualizing the interpretive process in curriculum studies". Journal of Curriculum Studies, 39(5), (pp. 537-558).

WEBER, Sandra (2008): "Visual Images in Research". En KNOWLES, J. G. y COLE, A. L. [eds.] (2008): Handbook of the Arts in Qualitative Research (pp. 41-53). Thousand Oaks, CA: Sage Publications.

\section{NOTA:}

El contenido de este artículo se deriva de la tesis doctoral Subjetividades en tránsito. La relación pedagógica como un encuentro conversacional entre sujetos en torno a la cultura visual que fue presentada en la Facultad de Bellas Artes de la Universidad de Barcelona el 26 de enero de 2012. 